\title{
A Straightforward Synthesis and Characterization of a New Poly(imide siloxane)-based Thermoplastic Elastomer
}

\author{
By Wen-Chang LIAW, ${ }^{1, *}$ Jung CHANG-CHIEN, Hung KANG, Yu-Lin CHENG, and Li-Wen FU
}

Three series of poly(imide siloxane) (PIS) copolymers were synthesized through straightforward simultaneous condensation reaction of pyromellitic dianhydride (PMDA), 2, 2'-bis[4-(3-aminophenoxy)phenyl] sulfone (m-BAPS) and three different number-average molecular weights $\left(M_{\mathrm{n}}=859,1152\right.$ and $\left.1619 \mathrm{~g} \cdot \mathrm{mol}^{-1}\right)$ of $\alpha, \omega$-bis (3-aminopropyl) polydimethyl siloxane (APPS). The effects of hard segment, polyimide (PI), on the properties of PIS copolymers were investigated. The prepared PIS copolymers possess the properties of thermal plastic elastomers. Microphase separation, affected by formulation, was found to be important phenomenon that determined the physical properties of the PIS copolymer. Mechanical measurement with the Instron-type tensile meter showed that the copolymers have elongation at break of up to 324\%. Two prepared samples (APPS $M_{\mathrm{n}}=859$, PI content of 15 and $20 \mathrm{wt} \%$ ) were found to exhibit good rubber property of being able to retract to original length upon release of the stress applied, others were characterized as plastics. The softening temperatures of the PIS thermoplastic elastomers ranged from 109 to $265^{\circ} \mathrm{C}$, and can easily be processed by extrusion or injection molding, and recycled.

KEY WORDS: Polysiloxane / Poly(imide siloxane)(PIS) / Copolymer / Thermoplastic Elastomer (TPE) / Microphase Separation /

In the field of rubber industry, thermoplastic elastomer (TPE) is a group of polymeric materials that exhibit elastomeric behavior at their service temperature and can be reprocessed by melting at elevated temperatures. ${ }^{1,2}$ Hence TPE is considered a recyclable material. Diminishing supply of materials and energy from nature has become increasingly severe. The urgency in the demand for recyclable and energy efficient materials has become increasingly high through the years. When comparing to conventional vulcanized rubber, TPE not only exhibits elasticity, but also provides energy saving processibility which is similar to injection moldable plastics. TPE can be recycled by simple melt mixing and extrusion and/or injection, and the process can be fully automated.

Polysiloxane rubbers have polymeric $\mathrm{Si}-\mathrm{O}-\mathrm{Si}$ backbone, which renders the material distinctive properties, such as good electric property, thermal stability, anti-oxidative property, durability at low temperatures, as well as ozone, weathering and radiation resistance. ${ }^{3}$ Although polysiloxane rubber has wide applications in the electronic, tubing and baby care industries, especially in the manufacturing of keyboards, the TPE of polysiloxane system has not yet been widely commercialized.

Mostly, the manufacture of polysiloxane rubber adopts one of the following processes. The first process is the widely used high temperature vulcanized process (HTV), in which the polysiloxane gum of high molecular weights were mixed and vulcanized with peroxide, reinforce filler and other additives prior to hot compress molding. The second was the twocomponent room temperature vulcanized process (RTV-2), in which a separately pre-measured amount of highly reactive crosslinking agent, was mixed with the polysiloxan/reinforce filler/additives mixture, and the blend was immediately poured into a mold at room temperature for crosslinking reactions up to several hours. The third process involved the use of two components of liquid siloxane (LS), one of which was dimethylmethylhydrogensiloxane copolymer and the other was vinyl-containing polydimethysiloxane. In this process, platinum complex was used to catalyze the hydrosilylation reaction in the reaction injection molding machine. ${ }^{3}$

An important common feature of these types of polysiloxane is that they are thermal setting polymers, and can not be reused by simple melt mixing process. The only way to recycle the material is through thermal pyrolysis to cyclosiloxane monomers at the expanse of thermal energy. As opposed to this, the recycle of TPE spared this part of thermal pyrolysis energy.

Generally, the chemical structure of TPE is characterized by a copolymer which is composed of an amorphous or low melting soft segment with a low glass transition temperature $\left(T_{\mathrm{g}}\right)$ and a solidified hard segment. Such coexisting, yet microscopically separated amorphous soft segment and solidified hard segment (microphase separation) is necessary for the copolymer to be a TPE. The hard segment is designed to play the role of physical crosslinkage at service temperature, while it can be melt at elevated temperature in melt-injection process.

In the manufacturing of polysiloxane TPE, polysiloxane was the only soft segment, whereas the choice of hard segment can be versatile. In the literature, there are not many reports about polysiloxane TPE. Kajiyama et al. ${ }^{4}$ have reported the synthesis and properties of multiblock copolymers based on poly (dimethylsiloxane) (PDMS) and $N$-phenylated polyureas (the hard segment). The oligomer of $\alpha, \omega$-bis (3-aminopropyl) polydimethylsiloxane (APPS, number-average molecular

${ }^{1}$ Department of Chemical and Materials Engineering, National Yunlin University of Science and Technology, 123, Section 3, University Road, Touliu, Yunlin 640, Taiwan, R.O.C.

*To whom correspondence should be addressed (Tel: +886-5-5342601-4618, Fax: +886-5-5312071, E-mail: Liawwc@yuntech.edu.tw). 
weight $M_{\mathrm{n}}=1720$ and $2740 \mathrm{~g} \cdot \mathrm{mol}^{-1}$ ) and $\alpha, \alpha^{\prime}$-dianilinop-xylene (DAX) were used to react with $4,4^{\prime}$-methylenebis (phenyl isocyanate) (MBI) by the solution polyaddition technique to synthesize several related multiblock copolymers. After casting from the chloroform solutions of copolymers or directly from the reaction solution just prepared, they have obtained a transparent, ductile and elastic film. The thermal behaviors (TGA curves) of all these films have been shown to have decomposition temperatures $\left(T_{\mathrm{d}}\right)$ lower than that of APPS and higher than that of the polyurea homopolymer prepared in their study.

Polyimide (PI) is considered as a high performance polymer materials by their unique properties, such as extremely high thermal stability, high mechanical strength and superior electric properties. It has been widely used in the industries of microelectronics, aerospace and other advanced technologies. ${ }^{5-10}$ The superior thermal and mechanical properties came mainly from the presence of abundant aromatic rings in the PIbackbone, which renders the polymer to be easily solidified.

Such character makes PI a good candidate to be used as the hard segment of TPE. ${ }^{11-13}$ Kricheldorf et al. ${ }^{11}$ synthesized poly(ether-ester-imides) TPE by the polycondensation of 1,4dihydroxybutane, poly(tetramethylene oxide) and a bisimide dicarboxylic acid based on 1,4-diaminobutane and trimellitic anhydride. Yeganeh et al. ${ }^{12}$ reported the preparation of poly(urethane-imide-imide) TPE via the reaction of isocyanate terminated polyurethane with $2,2^{\prime}$-pyromellitdiimidodisuccinic anhydride chain extender. Takeichi et al. ${ }^{13}$ prepared the high performance poly(urethane-imide) TPE from amine or anhydride-terminated oligoimide and isocyanate-terminated polyurethane prepolymers. They had found that when the copolymer films with of PI content less than $30 \%$, the copolymer became elastomer, and the copolymer films became plastic when PI content was higher than $36 \%$. In these copolymers, PI successfully played the role of hard segment in the TPE.

In the family of TPE, the copolymers of poly (imide siloxane) (PIS) is another branch that is worth investigating. Generally, PIS copolymers are prepared by copolymerizing PDMS with PI. PIS copolymers have been synthesized by a number of different methods. ${ }^{14-17}$ One of the frequently used method is the condensation of an aromatic tetracarboxylic dianhydride with an aromatic diamine and polysiloxane diamine, such as APPS, to prepare the polysiloxane-containing poly(amic acid) (PAAS), which is then imidized at elevated temperature to form PIS copolymer.

Thus far, there are a few published reports dealing with the application of PIS copolymers on TPE. Andre et al. ${ }^{18-22}$ reported a series of studies about fluorinated TPE. They used allyl group telechelic PI moiety and various size of hydrosilane telechelic polyhybridsiloxane, through hydrosilylation reaction, to prepare a series of PIS alternating block copolymers containing 36, 54 and $75 \mathrm{wt} \%$ of PI. ${ }^{18}$ The resulting PIS copolymers exhibited good performances in terms of both thermomechanical and chemical properties.

Alternatively, they used the oligomers of $\alpha, \omega$-diallylfluorinated PI and $\alpha, \omega$-dihydrosilane fluorinated-polyhybridsiloxane to synthesize a series of alternating fluorinated PI-fluorinated polyhybridsiloxanes block copolymers. ${ }^{20}$ In another reports of theirs, ${ }^{21}$ they used $\alpha, \omega$-dichlorosilane fluorinated PI and $\alpha, \omega$ disilanol polyhybridsiloxanes to synthesize fluorinated PI/ fluorinated polyhybridsiloxane block copolymers through a two-step polycondensation reaction. They observed phase separation in these fluorinated block copolymers. The copolymers exhibited low surface tension and good thermal stability. The length of the soft-segment was found to be positively correlated to the thermo mechanical property of the TPE material.

In our previous reports, ${ }^{23-25}$ it was found that when the content of PDMS (minor component) in PIS copolymers was higher than $2.7 \mathrm{~mol} \%$ (prepared from the diamine mixture of APPS and 2, 2'-bis[4-(3-aminophenoxy) penyl] sulfone

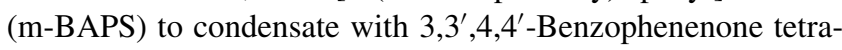
carboxyilc dianhydride (BTDA)), microphase separation between PI and PDMS segments was detected. This could be attributed to the large difference of solubility parameters between these two homopolymers. ${ }^{26}$ However, when PI was the minor component, it will be interesting to know whether or not, microphase separation will occur at specific PI content.

In designing TPE for various applications, the choice of the soft segment and hard segment is as important as the investigation of the processing conditions. Based on our previous observations with PIS, and the generally recognized thermoplastic properties of the used PI segment from condensation between m-BAPS and PMDA, it was expected that these PIS copolymer might have potential application as TPE. Such expectation was based on the fact that the polysiloxane moiety inherits the silicone rubber characteristic, which is suitable to serve as the soft segment, and the PI moiety is known for being easily solidified, which may make it suitable to fit in the TPE as the hard segment.

In this study, we followed the track of our previous researches about PIS. ${ }^{27}$ In our preliminary experiment, the prepared PIS copolymers even behaved like rubber at low PI content. We therefore tried to develop a new type of TPE based on PIS copolymer, using a strategy that's different from the ones proposed above. Briefly, a strategy that uses APPS of three different number average molecular weights $\left(M_{\mathrm{n}}\right)$ to mix with various amount of m-BAPS, then condensate with PMDA.

\section{EXPERIMENTAL}

\section{Materials}

2,2'-bis[4-(3-aminophenoxy)phenyl] sulfone (m-BAPS, 97\%) was purchased from Tokyo Chemical Industry Co., LTD. Pyromellitic dianhydride (PMDA, 97\%), was purchased from Aldrich and was purified by recrystallization from acetic anhydride before use. Octamethylcyclotetrasiloxane (D4, 97\%), 1,3-bis(3-aminopropyl) tetramethyl disiloxane (BAPDS, 97\%) were purchased from United Chemical Technologies, and tetramethylammonium hydroxide pentahydrate (98\%) was purchased from Lancaster Synthesis Ltd and other chemicals and solvents were used as received. 


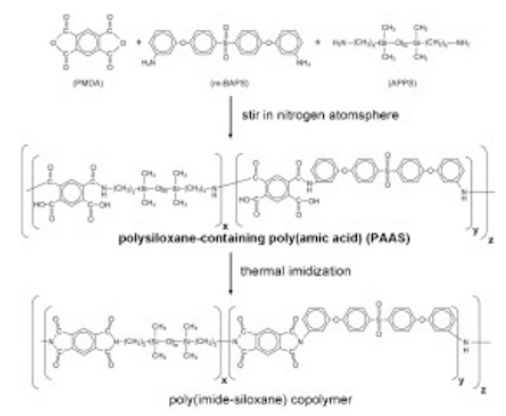

Scheme 1. Preparation of PIS copolymers.

Preparation of $\alpha, \omega$-bis(aminopropyl) Terminated Polydimethyl Siloxane(APPS) Oligomers

Various number average molecular weights of APPS oligomers were synthesized by anionic equilibration polymerization of D4, with BAPDS as terminating agent, in the presence of catalyst. The reaction was conducted at $80^{\circ} \mathrm{C}$ for $24 \mathrm{~h}$ to form homogeneous reaction mixture, the temperature was then increased to $150^{\circ} \mathrm{C}$ and maintained for $4 \mathrm{~h}$ to decompose the catalyst. After cooling, the homogeneous mixture was vacuum stripped at $110^{\circ} \mathrm{C}$ for $2 \mathrm{~h}$ to remove unreacted $\mathrm{D}_{4}$. The number average molecular weight of APPS, $M_{\mathrm{n}}$, was determined by gel permeation chromatography (GPC) and the structure was characterized by FT/IR and ${ }^{1} \mathrm{H}-\mathrm{NMR}$. $M_{\mathrm{n}}$ was controlled by adjusting the mole ratio of $\mathrm{D}_{4}$ and BAPDS.

\section{Preparation of Polysiloxane-containing Poly(amic acid)}

The polysiloxane-containing poly(amic acid) (PAAS) used in this study was prepared from APPS $\left(M_{\mathrm{n}}=859,1152\right.$ and 1619), m-BSPDA and PMDA by solution polycondensation reaction. PMDA was reacted with APPS oligomer and mBSPDA in NMP solvent at room temperature for $5 \mathrm{~h}$. The molar ratio of the dianhydride and total diamine for the reaction was kept at 1:1. The solid content of the solution was controlled at $18 \%$. The preparation method was shown in Scheme 1 .

\section{Preparation of poly(imide siloxane) copolymers}

The poly(imide siloxane) (PIS) copolymers were prepared from the above prepared PAAS solution by casting method. The PAAS solution was coated on glass plate and dried to remove the solvent at $80^{\circ} \mathrm{C}$ for $1 \mathrm{~h}$. After peeling off the polymer film from the glass, the film was transfer to a Teflon coated stainless frame followed by thermal imidization in a vacuum oven at temperatures of $100,150,200,250$ and $300^{\circ} \mathrm{C}$, each for $1 \mathrm{~h}$ to form PIS copolymers.

\section{Characterization:}

The number average molecular weights of the APPS oligomers were determined by Jasco RI-930 gel permeation chromatography (GPC) with a refractive index detector. Determination of the number average molecular weights was done by calibration against polystyrene standards.
The ${ }^{1} \mathrm{H}-\mathrm{NMR}$ spectra were recorded with a Bruker AM300WB NMR spectrometer. The solvent used was deuterium chloroform $\left(\mathrm{CDCL}_{3}\right)$, containing tetramethylsilane (TMS) as internal shift reference.

FT/IR spectra were recorded on a PerkinElmer FT/IR spectrometer. Film thickness of each sample was controlled at $10 \mu \mathrm{m}$ by a film thickness controlling device (wire bar coater) widely used in the ink and paint industries. Microscopic images of the fracture surface of PIS copolymer were taken on a JEOL JSM-6700F field emission scanning electron microscope (FESEM). All samples were coated with gold in vacuum and mounted on aluminium mounts with carbon paste.

The softening temperature was measured by using a TAInstruments DMA 2980 dynamic mechanical analyzer (DMA) under controlled force mode. Degradation and thermal stability of the copolymers were monitored with a TA-Instruments TGA thermal analyzer 2050. The thermo-gravimetric (TGA) measurements were carried out under an $\mathrm{N}_{2}$ atmosphere at a heating rate of $20^{\circ} \mathrm{C} / \mathrm{min}$ from 40 to $800^{\circ} \mathrm{C}$. The tensile strength and elongation at break of samples were obtained from the stress/ strain curve measured with a Chen Yen TS-01 mechanical testing instrument.

\section{RESULTS AND DISCUSSIONS}

One important structural feature of TPE was the copolymerization of soft segment and hard segment. For the hard segment to serve its purpose in contributing the important physical crosslinkages in TPE, the hard segment should be able to solidify in the cooling process after injection molding. PI is well known for possessing high melting temperature and, due to its overwhelmingly rich content of aromatic rings in the backbone, can be solidified easily. Together with PI's high thermal resistance and dielectric constant, the presence of PI in the copolymers would hopefully provide these desirable physical properties.

The characteristic chemical structure of PIS copolymers generally consist of hard segment (mainly composed of aromatic and imide rings) and soft segment (mainly composed of siloxane $\mathrm{Si}-\mathrm{O}$ chain type structure), as shown in Figure 1. In order to obtain a PIS copolymer with TPE properties, the selected thermoplastic PI were synthesized from m-BAPS and PMDA. To further study the patterns of how the molecular size of APPS affected the PIS copolymer's TPE properties, three different $M_{\mathrm{n}}$ of APPS were synthesized and characterized $\left(M_{\mathrm{n}}=859,1152\right.$ and $\left.1619 \mathrm{~g} \cdot \mathrm{mol}^{-1}\right)$. They were synthesized from octamethylcyclotetrasiloxane $\left(\mathrm{D}_{4}\right)$ as the monomer, and 1,3-bis (aminopropyl) tetramethyl disiloxane (BAPDS) as the terminating agent, and with an ammonium catalyst by anionic

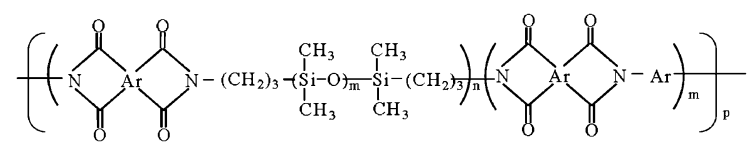

Figure 1. Representative structure of PIS copolymers. 
equilibrium polymerization reaction. The $M_{\mathrm{n}}$ of APPS were controlled by controlling the molar ratio of $\mathrm{D}_{4}$ to BAPDS. The catalyst was decomposed by heating (to $150^{\circ} \mathrm{C}$ ) after equilibrium, then, unreacted $\mathrm{D}_{4}$ were removed by vacuum distillation. The structure and $M_{\mathrm{n}}$ of the prepared APPS were verified by FT/IR, ${ }^{1} \mathrm{H}-\mathrm{NMR}$ and GPC respectively (Data not shown).

The prepared APPS were used with m-BAPS at various ratios to condensate with PMDA to synthesize three series of polysiloxane containing polyamic acid (PAAS) solution in NMP, which were then casted, and were followed by step thermal imidization to prepare PIS copolymers with designed ratios of soft segment and hard segment. The reaction process was shown in Scheme 1. Since in each hard segment, there are equimolar of PMDA and m-BAPS, the wt $\%$ of hard segment can be calculated by adding the weight of m-BAPS with that of equimolar of PMDA, minus the amount of water lost during condensation, and divided by the total weight of the copolymer. The wt \% of hard segment plays a role that is as important as the $M_{\mathrm{n}}$ of APPS in determining the TPE properties of the PIS copolymers. The compositions of the three series copolymers were summerizd in Table I.

The chemical structures of PAAS and PIS were confirmed by FT/IR (Figure 2). The morphological, thermal and mechanical properties of the prepared PIS copolymers are characterized and discussed in details in the following sections.

\section{FT/IR characterization}

FT/IR can be used to monitor chemical changes involved in polymer synthesis. The method was used to verify the synthesis of PAAS, and subsequent conversion of PAAS to PIS copolymers. Figure 2 compared the FT/IR spectra of PIS-859-25 copolymer and its precursor of PAAS. The characteristic absorption peaks of PAAS showed an O-H stretching at $3600-3200 \mathrm{~cm}^{-1}$ and a $\mathrm{C}=\mathrm{O}$ stretching at $1723 \mathrm{~cm}^{-1}$ of an

Table I. Compositions of the three series of PIS copolymers

\begin{tabular}{lcccc}
\hline \multirow{2}{*}{ sample code } & \multicolumn{3}{c}{ wt \% of monomer } & \multirow{2}{*}{$\begin{array}{c}\text { wt \% of PI } \\
\text { (hard segment) }\end{array}$} \\
\cline { 2 - 4 } & APPS & m-BAPS & PMDA & 100 \\
\hline PI & 0 & 3.4 & 6.6 & 15 \\
PIS-859-15 & 68 & 10 & 22 & 19 \\
PIS-859-20 & 65 & 13 & 22 & 24 \\
PIS-859-25 & 60 & 17 & 23 & 29 \\
PIS-859-30 & 56 & 20 & 24 & 34 \\
PIS-859-35 & 52 & 23 & 25 & 15 \\
\hline PIS-1152-15 & 71 & 10 & 19 & 20 \\
PIS-1152-20 & 67 & 13 & 20 & 24 \\
PIS-1152-25 & 63 & 17 & 20 & 29 \\
PIS-1152-30 & 59 & 20 & 21 & 34 \\
PIS-1152-35 & 55 & 23 & 22 & 15 \\
\hline PIS-1619-15 & 75 & 10 & 15 & 20 \\
PIS-1619-20 & 70 & 13 & 17 & 24 \\
PIS-1619-25 & 66 & 16 & 18 & 39 \\
PIS-1619-30 & 62 & 20 & 18 & 34 \\
PIS-1619-35 & 57 & 23 & 20 & \\
\hline
\end{tabular}

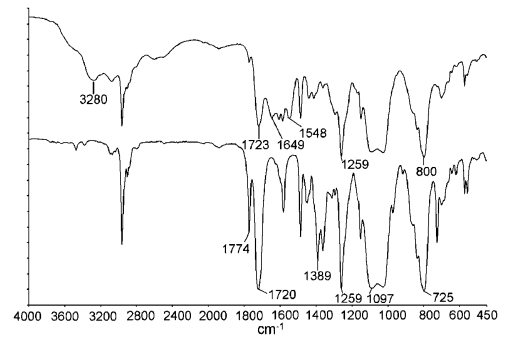

Figure 2. FT/IR spectra of PIS-859-25 copolymers and it precursor of PAAS.

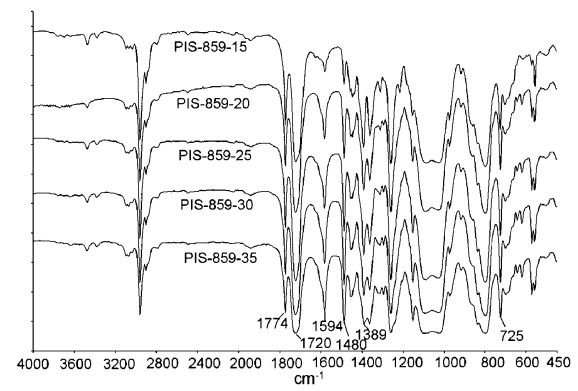

Figure 3. FT/IR spectra of PIS-859 series copolymers.

acid group. Meanwhile, absorption peaks for N-H stretching at $3280 \mathrm{~cm}^{-1}, \mathrm{C}=\mathrm{O}$ stretching at $1649 \mathrm{~cm}^{-1}$ and OC-NH stretching at $1548 \mathrm{~cm}^{-1}$ signified typical absorption peaks of an amide linkage. The disappearance of these peaks in the spectra of PIS copolymers testified the progress of the imidization reaction.

The spectra of PIS copolymers exhibited the characteristic absorption peaks of imide group at 1774 and $1720 \mathrm{~cm}^{-1}$ due to the asymmetric and symmetric stretching of carbonyl groups, while 1389 and $725 \mathrm{~cm}^{-1}$ corresponded to the vibrations of cyclic imides. The characteristic absorption peaks of polysiloxane segment at $1259(\mathrm{Si}-\mathrm{C})$ and $1097 \mathrm{~cm}^{-1}(\mathrm{Si}-\mathrm{O}-\mathrm{Si}$ stretching) can also be observed.

Figure 3 compared the FT/IR spectra of the copolymers of PIS-859 series with different PI (hard segment) content. In order to visualize the general trend upon changing the PI content, we fine tuned the instrument so that the carbonyl stretching absorption (1774, $1720 \mathrm{~cm}^{-1}$ ) of each sample remained virtually constant. Under such circumstance, the carbonyl stretching absorption can serve as the internal standard in observing the relative intensities of other peaks with acceptable error, and peak intensities of phenyl groups $\left(1480,1594 \mathrm{~cm}^{-1}\right)$ were cross referenced to them.

In Figure 3, the intensities of the absorption peaks at 1594 and $1480 \mathrm{~cm}^{-1}$ (aromatic skeletal vibrations) gradually increased, in accordance with the content of PI hard segment (resulted in increased content of phenyl rings from m-BAPS). Comparatively, looking at the intensities of the characteristic absorption peaks of imide groups at 1774 and $1720 \mathrm{~cm}^{-1}$, which resided in both soft and hard segments in approximately equal number for these PIS copolymers, showed virtually no variations among them. 


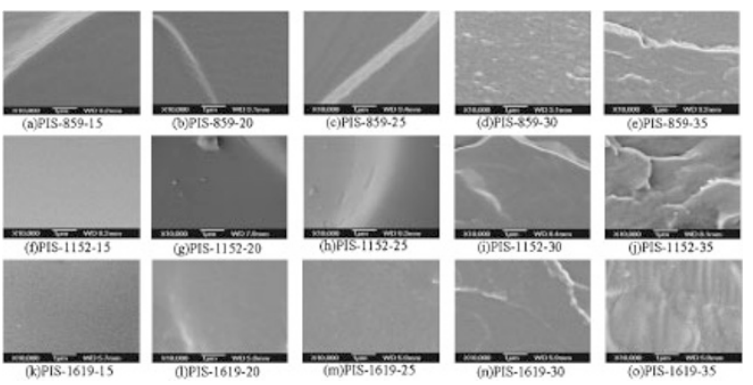

Figure 4. SEM photographs $(\times 10,000)$ of the fracture surfaces of PIS copolymers.

\section{Morphology of PIS copolymers}

For a good thermoplastic elastomer, it is desirable to have morphological microphase separation. FESEM micrographs can be used to study microscopic structural and morphological status of materials. In this study, FESEM micrograph was used, as one of the tools (film transmittance and $T_{\mathrm{g}}$ were also used in this study), to judge the occurrence of microphase separation, a phenomenon important in discussing the homogeneity of copolymers. The FESEM micrograph of the fracture surface of the three series of PIS copolymers with various hard segment contents are shown in Figure 4. Comparing these micrographs, it is not hard to see that there are microstructural differences between these PIS copolymers. The copolymers with high ratios of hard segment (PI content of 20 to $35 \mathrm{wt} \%$ ) exhibited apparent microphase separation. This indicated insufficient compatibility between the two phases (soft and hard segments) of these copolymers, which may be desirable in some applications.

Oppositely, for PIS-1152 and PIS-1619 series, when the hard segment content was decreased to $15 \mathrm{wt} \%$, a homogeneous morphology was observed. It is quite likely that before imidization, low content of PAA (PI hard segments precursor) were dispersed as small particles. However, during imidization, PI formation gradually took place, and formed PI tends to aggregate in the bulk phase of molten copolymer solution.

The molten viscosity during imidization is directly influenced by $M_{\mathrm{n}}$ of either the PIS copolymer or APPS segment, or both, as well as PI content. Since the molecular weights $\left(M_{\mathrm{n}}\right)$ of the three series PIS copolymers were not significantly different (ranged between 10500 and 12500, measured by GPC, data not shown), its influence, during imidization, could be minor, and changes in molten viscosity may mainly be attributed to $M_{\mathrm{n}}$ of APPS, under the circumstance of the same PI content. Although stronger proves are required, the speculation of different molten viscosity during imidization could explain the observed phase separation.

In case of the same PI content (15wt \%), different molten viscosities would most likely come from differences in the $M_{\mathrm{n}}$ of APPS. It is harder for PI to aggregate in a more viscous environment, as with larger $M_{\mathrm{n}}$ of APPS (the PIS-1152 and PIS-1619 series) than in a less viscous environment, as with smaller $M_{\mathrm{n}}$ of APPS (the PIS-859 series). The viscosity effect hindered such PI aggregation to form an isolated phase in the

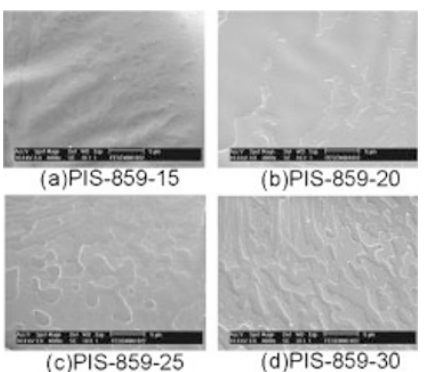

Figure 5. SEM photographs $(x 4,000)$ of the fracture surfaces of the representative PIS-859 series.

more viscous polysiloxane phase (the PIS-1152 and PIS-1619 series) and a homogeneous morphology was observed.

However, in all of the PIS-859 series copolymers, even with the PI content down to $15 \mathrm{wt} \%$, minor degree of microphase separation was observed. The observation of heterogeneous morphology or with slight microphase separation in the cases of PIS-859-15 and PIS-859-20 may come from the lower $M_{\mathrm{n}}$ of APPS. Since, when the low hard segment content was accompanied with low $M_{\mathrm{n}}$ of APPS, the viscosity effect of APPS was not strong enough to prohibit the migration of the PAA precursor segments which, before imidization, were so finely divided that they virtually behaved like a single phase. However, this presumption calls for the need of more solid proof. Under such circumstance, the imidized PI particles tend to aggregate, the slightly isolated microphase would start to grow, and the heterogeneity (microphase separation) of the copolymer would increase accordingly.

At high resolution power $(\times 10,000)$ in Figure 4 , such microphase separations were less observable. It is more apparent at lower resolution power $(\times 4,000)$, as in Figure 5 . Figure 5 revealed that the degree of microphase separation of the PIS-859 series decreased with decreasing PI content. The PI domain in the PIS-859-15 and PIS-859-20 copolymers was expected to play the role of providing physical crosslinkage in the PIS copolymer, which in turn, would render the PIS copolymers rubber properties, which is not commonly seen in such type of PIS copolymer TPE.

Another effect of PI is that its presence is likely to bring to the copolymer changes in the light transmitting property. Take, for example, the data for PIS-859-15, PIS-1152-15 and PIS$1619-15$ in Table II, the maximum transmittances at $650 \mathrm{~nm}$ were $38 \%, 42 \%$ and $44 \%$ respectively. The variations among the transmittances may seem to be minor. However, as stated

Table II. The maximum optical transmittance (T\% at $650 \mathrm{~nm})$ of the three series of PIS copolymer sheets $(0.5 \mathrm{~mm}$ thick)

\begin{tabular}{cccccc}
\hline $\begin{array}{c}\text { sample } \\
\text { code }\end{array}$ & $\begin{array}{c}\text { maximum } \\
\mathrm{T}(\%)\end{array}$ & $\begin{array}{c}\text { sample } \\
\text { code }\end{array}$ & $\begin{array}{c}\text { maximum } \\
\mathrm{T}(\%)\end{array}$ & $\begin{array}{c}\text { sample } \\
\text { code }\end{array}$ & $\begin{array}{c}\text { maximum } \\
\mathrm{T}(\%)\end{array}$ \\
\hline PIS-859-15 & 38 & PIS-1152-15 & 42 & PIS-1619-15 & 44 \\
PIS-859-20 & 36 & PIS-1152-20 & 39 & PIS-1619-20 & 39 \\
PIS-859-25 & 35 & PIS-1152-25 & 38 & PIS-1619-25 & 34 \\
PIS-859-30 & 35 & PIS-1152-30 & 37 & PIS-1619-30 & 30 \\
PIS-859-35 & 32 & PIS-1152-35 & 33 & PIS-1619-35 & 24 \\
\hline
\end{tabular}


above that, PI is easier to aggregate in the less viscous PIS imidization mixture (when lower APPS $M_{\mathrm{n}}$ of 859 was used) than in the more viscous imidization mixture (when higher APPS $M_{\mathrm{n}}$ of 1152 and 1619 were used), and such aggregation may increase the degree of microphase separation.

The optical transmittance increased with increasing $M_{\mathrm{n}}$ of APPS for PI content of $15 \mathrm{wt} \%$. Oppositely, for PI content of $35 \mathrm{wt} \%$, the optical transmittance decreased with increasing $M_{\mathrm{n}}$ of APPS. This result could be explained by the differences of the morphology (homogeneous or microphase separation). The existence of differences among PI domain sizes for different PI contents can be seen in Figure 5 (for the PI-859 series), but due to morphological irregularities, we can not be definitive about the exact domain size.

Besides FESEM micrographs and transmittance, the presence of microphase separation can also be justified by studying other physical properties such as glass transition temperature and mechanical properties. Theoretically, the presence of multiple phases (microphase separation) in a copolymer would lead to more than one glass transition temperature. Also, for a thermoplastic elastomer to exhibit rubbery property, appropriate microphase separation is required, since the structure of a physical crosslinkage interweaved soft segments is essential in rubbers. These will be discussed shortly.

\section{Thermal Properties}

There are several aspects in studying thermal properties of copolymers, and each has its own physical significance. In this research, the soften temperatures decomposition temperatures, weight residues and glass transition temperatures of the three series of PIS copolymers were studied.

\section{SOFTEN TEMPERATURE}

The soften temperature of polymers is important when the copolymers are used as thermoplastic elastomers that can be processed in molten state. The soften temperature can be obtained from the curves of copolymeric dimensional changes versus temperatures in DMA measurement, as shown in Figure 6 for the copolymers of PIS-1619 series. All of the soften temperatures of three series PIS copolymers prepared in this study were listed in Table III.

Figure 7 depicted the soften temperatures of three PIS copolymers series as a function of the weight percent of PI

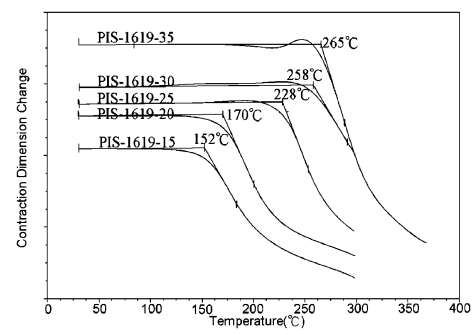

Figure 6. Curves of dimension change vs. temperature for PIS-1619 series copolymers.
Table III. Thermal properties of the three series of PIS copolymers

\begin{tabular}{cccccc}
\hline sample code & $\begin{array}{c}\text { softening } \\
\text { temperature }\end{array}$ & $T_{\mathrm{d}}(5 \%)^{(\mathrm{a})}$ & $\begin{array}{c}\text { weight residue } \\
(\%) \\
\text { at } 800^{\circ} \mathrm{C}\end{array}$ & $T_{\mathrm{g}} 1^{(\mathrm{b})}$ & $T_{\mathrm{g}} 2^{(\mathrm{b})}$ \\
\hline Pure PI & - & 570 & 56 & - & 253 \\
\hline PIS-859-15 & 109 & 462 & 13 & -103 & -14 \\
PIS-859-20 & 117 & 462 & 17 & -100 & -9 \\
PIS-859-25 & 123 & 463 & 19 & -95 & -2 \\
PIS-859-30 & 153 & 464 & 24 & -97 & 0 \\
PIS-859-35 & 158 & 472 & 28 & -100 & -1 \\
\hline PIS-1152-15 & 113 & 466 & 13 & -104 & - \\
PIS-1152-20 & 129 & 468 & 15 & -101 & -22 \\
PIS-1152-25 & 145 & 469 & 17 & -102 & -23 \\
PIS-1152-30 & 161 & 472 & 21 & -103 & -15 \\
PIS-1152-35 & 174 & 475 & 23 & -102 & -9 \\
\hline PIS-1619-15 & 152 & 472 & 11 & -109 & - \\
PIS-1619-20 & 170 & 479 & 13 & -111 & -65 \\
PIS-1619-25 & 228 & 479 & 14 & -107 & -43 \\
PIS-1619-30 & 258 & 480 & 20 & -109 & -37 \\
PIS-1619-35 & 265 & 480 & 21 & -109 & -35 \\
\hline
\end{tabular}

(a) The temperature at weight loss of $5 \%$. (b) Glass transition temperature was determined by dynamic mechanical analyzer (DMA).

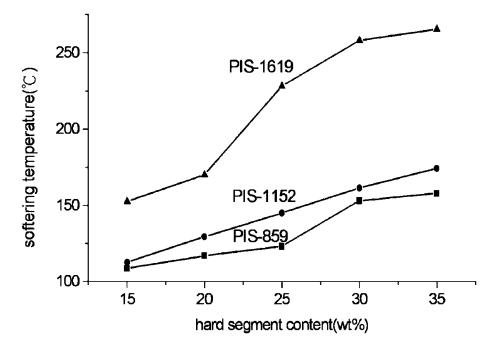

Figure 7. Relationship between hard segment content and softening temperature of three series PIS copolymers.

segment. The figure revealed that all of the soften temperatures of PIS copolymers shared a similar trend that the soften temperature increased with increasing weight percent of PI segment. This phenomenon was in agreement with the facts that PI is easily solidified, and is supposed to provide higher intermolecular interactions, or physical crosslinkage in PIS copolymers. When the PI content in the PIS copolymers was increased, the density of physical crosslinkage was increased accordingly, and led to an increased soften temperature. For the PIS copolymers with the same PI content, the soften temperature increased with increasing $M_{\mathrm{n}}$ of APPS. This may come from the decreased proportion of the PDMS soft domain that is left outside the compatibilized PI and PDMS domain. More discussions regarding this will be given in the $T_{\mathrm{g}}$ section. From the viewpoint of manufacture, lower soften temperature indicates easier processing. But the product's limit of working temperature will be low.

\section{DECOMPOSITION TEMPERATURE $\left(T_{\mathrm{d}}\right)$}

$T_{\mathrm{d}}$ is another important index in discussing thermal stability of polymers. TGA was used to study $T_{\mathrm{d}}$ of the three series of PIS copolymers. Figure 8 showed the TGA curves for the PIS- 


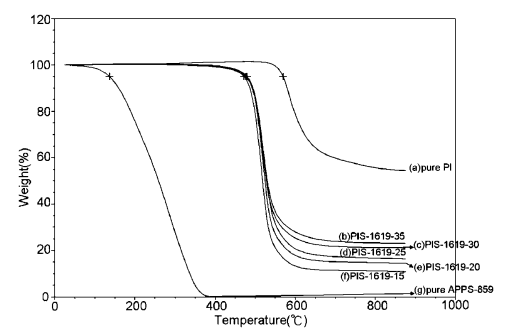

Figure 8. The TGA curves of PIS-1619 series copolymers (weight \% vs. temperature).

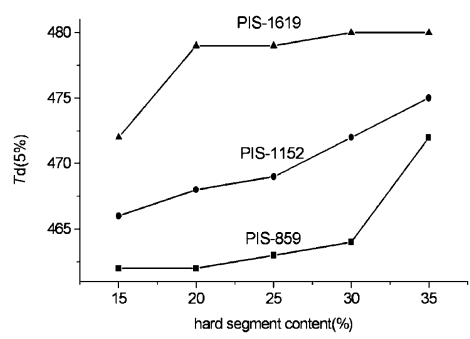

Figure 9. Relationship between hard segment content and thermal degradation temperature $T_{\mathrm{d}}(5 \%)$.

1619 series copolymer (due to similarity, TGA curves for the other two series were not shown here). $T_{\mathrm{d}}$ at $5 \%$ weight loss, for the three series PIS copolymers, were listed in Table III. All of the $T_{\mathrm{d}}$ fell in the range of 460 to $480^{\circ} \mathrm{C}$. In each series, $T_{\mathrm{d}}$ increased with increasing hard segment contents (Figure 9). As with the soften temperature, such trend could be attributed to the high thermal stability of the PI segment. While, the $T_{\mathrm{d}}$ of the copolymers would approach toward that of the PI homopolymer $\left(570^{\circ} \mathrm{C}\right)$ upon increasing amount of PI segment incorporation into the molecular chains of polysiloxane. This result is consistent with our previous observations ${ }^{20}$ that in the case of polysiloxane segmented PI, incorporation of flexible polysiloxane to the PI backbone would lead to a lower thermal stability than pure PI.

\section{WEIGHT RESIDUE}

The residual weights of the prepared PIS copolymers after heating to $800^{\circ} \mathrm{C}$ at a heating rate of $20^{\circ} \mathrm{C} / \mathrm{min}$ in nitrogen atmosphere were listed in Table III. Comparing weight residues of various samples in Table III, it showed that the weight residues increased with increasing PI content and fell in the neighborhood of half of the wt $\%$ of PI content. This result is consistent with the report by Tiwari et al. ${ }^{28}$ which pointed out that the residues obtained after complete decomposition at $900{ }^{\circ} \mathrm{C}$ in nitrogen atmosphere were $53 \%$ and $2.5 \%$ for pure PI and PDMS respectively. In this case of blending PMDS with PI, it was reported that the weight residues were 44.51 and $42.82 \%$ when the percentages of PDMS in blends were 20 and $25 \%$ respectively. This phenomenon may come from the phenyl ring structure of aromatic dianhydride and diamine presented in PI, and the conversion of polysiloxane to ceramic type of structure at elevated temperature. ${ }^{29}$

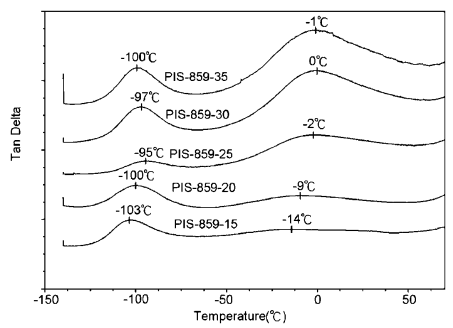

Figure 10. Temperature dependence of $\tan \delta$ for PIS-859 series copolymers.

\section{GLASS TRANSITION TEMPERATURE $\left(\boldsymbol{T}_{\mathrm{g}}\right)$}

Generally, for the determination of $T_{\mathrm{g}}$, DMA is more sensitive than the calorimetric method. The temperature dependences, below $70^{\circ} \mathrm{C}$, of $\tan \delta$ for the series of PIS-859 copolymers, measured by DMA, were shown in Figure 10, in which the peak temperatures represented the $T_{\mathrm{g}}$ of these copolymers, in the temperature range of concerns.

Since similar patterns were observed for the three series of copolymers, only the set of curves for the PIS-859 series were presented in Figure 10, and the $T_{\mathrm{d}}$ data were summarized in Table III for comparison. A general trend, for the PIS-859 series, in Figure 10 can be observed is that on each curve, two peaks could be observed. The magnitude or height of the $T_{\mathrm{g}} 2$ peaks decreased as we went from high (35\%) to low (15\%) PI content for the three PIS series studied. Parallel to this, the same trend was observed as we went from low $M_{\mathrm{n}}$ (859) to high $M_{\mathrm{n}}(1619)$ of APPS. The $T_{\mathrm{g}} 2$ peaks gradually became less identifiable for PIS-1151-15 and PIS-1619-15 (Table III). Since multiple $T_{\mathrm{g}}$ reflected the presence of microphase separation, the diminishing $T_{\mathrm{g}} 2$ in the curves for PIS-1152-15 and PIS-1619-15 may be another evidence for the absence of microphase separation in these two copolymers.

Regarding Figure 10 and Table III, another phenomenon worth mentioning here is the shifts of $T_{\mathrm{g}} 2$ towards lower temperature as we went from high PI content (35\%) to low PI content (15\%). This trend was unanimous for the three series of PIS copolymers under investigation. Such shifts of $T_{\mathrm{g}} 2$ could be explained by the decreased influence of PI on the copolymer when PI content was decreased, and $T_{\mathrm{g}} 2$ shifted in the direction to that of PDMS $\left(-123^{\circ} \mathrm{C}\right)$.

Accordingly, $T_{\mathrm{g}} 1$ may correspond to the molecular motions in the siloxane domain. $T_{\mathrm{g}} 2$ ranged form -65 to $0{ }^{\circ} \mathrm{C}$, which is far below that of pure PI $\left(253^{\circ} \mathrm{C}\right)$. This may partially prove the formation of a compatibilized PDMS and PI phase with slight microphase separation (of PDMS). In other words, since PI presented in the copolymer as the minor component, the PI segments are most likely to be well dispersed in the compatibilized phase. Although further investigation is needed, it seems appropriate at this stage to assume that $T_{\mathrm{g}} 2$ correspond to the molecular motions in the compatibilized PDMS and PI phase (or domain).

Additionally, comparing the three sets of data in Table III, it showed that as the molecular sizes of APPS increased from $M_{\mathrm{n}}$ of 895 to $M_{\mathrm{n}}$ of $1619, T_{\mathrm{g}} 2$ shifted towards lower 


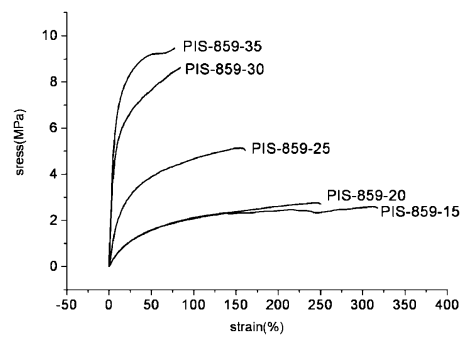

Figure 11. Stress-strain curves of PIS-859 series copolymers.

Table IV. Mechanical properties of the three series of PIS copolymers

\begin{tabular}{cccc}
\hline sample code & $\begin{array}{c}\text { tensile strength } \\
(\mathrm{MPa})\end{array}$ & $\begin{array}{c}\text { elongation } \\
\text { at break(\%) }\end{array}$ & $\begin{array}{c}\text { Young's modulus } \\
(\mathrm{MPa})\end{array}$ \\
\hline PIS-859-15 & 2.6 & 324 & 4.0 \\
PIS-859-20 & 2.8 & 255 & 4.1 \\
PIS-859-25 & 5.1 & 164 & 16 \\
PIS-859-30 & 8.6 & 84 & 85 \\
PIS-859-35 & 9.5 & 77 & 103 \\
\hline PIS-1152-15 & 2.5 & 183 & 3.2 \\
PIS-1152-20 & 2.5 & 136 & 4.3 \\
PIS-1152-25 & 3.0 & 131 & 8.2 \\
PIS-1152-30 & 5.8 & 79 & 21 \\
PIS-1152-35 & 9.3 & 72 & 60 \\
\hline PIS-1619-15 & 1.3 & 110 & 2.3 \\
PIS-1619-20 & 1.6 & 105 & 4.5 \\
PIS-1619-25 & 2.2 & 100 & 6.1 \\
PIS-1619-30 & 3.6 & 68 & 7.4 \\
PIS-1619-35 & 6.2 & 63 & 13 \\
\hline
\end{tabular}

temperatures. The details of how the molecular size of APPS affected the polymer's thermal behavior is currently under investigation.

\section{Mechanical Properties}

The tensile properties of three series of PIS copolymers were measured and the stress-strain curves of PIS-859 series copolymers were shown in Figure 11 (curves for the other two series of copolymers were similar and were not shown in this figure). For the three series of the prepared PIS copolymers, the tensile strength, tensile modulus and elongation at break were in the range of $1.3-9.5 \mathrm{MPa}, 2.3-103 \mathrm{MPa}$ and $63-324 \%$ respectively. The data of mechanical properties were summarized in Table IV, and were compared in Figures 12-14.

\section{TENSILE STRENGTH AND ELONGATION}

Figure 12 showed that the three series of copolymers shared the same trend that tensile strengths could be significantly enhanced by increasing the PI content (the hard segment). It is very likely that the commonly recognized strong intermolecular attraction and high mechanical strength of PI homopolymer was responsible for the enhancement of tensile strength of PIS copolymers. On the other hand, increase the chain length $\left(M_{\mathrm{n}}\right)$ of APPS in the soft segment was expected to decrease the tensile strength, and the corresponding three curves for the three sizes of APPS ( $M_{\mathrm{n}}$ of 859, 1152 and 1619)

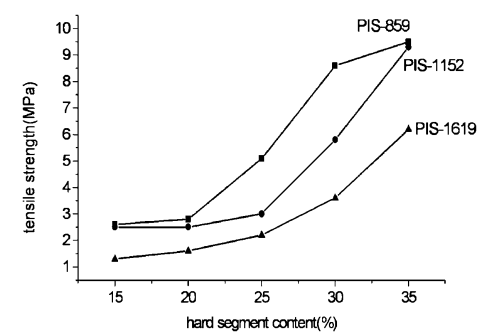

Figure 12. Relationship between tensile strength and hard segment content of PIS copolymers.

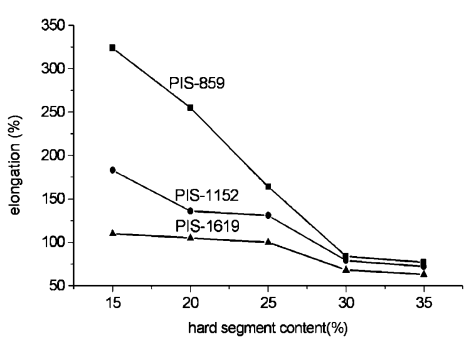

Figure 13. Relationship between elongation and hard segment contents of PIS copolymers.

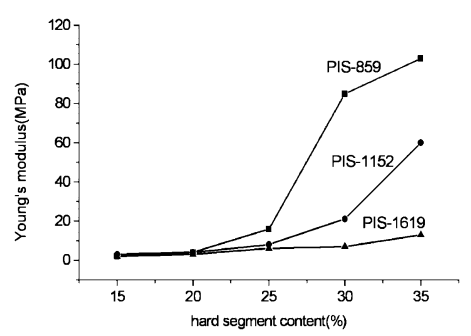

Figure 14. Relationship between Young's modulus and soft segment contents of PIS copolymers.

in Figure 12 agreed with this expectation.

Generally speaking, as the tensile strength of a polymer increases, most likely the polymer would exhibit low percent of elongation at break. In the three series of the prepared PIS copolymers, the elongation data shown in Table IV and Figure 13 have the same tendency as this statement that, for the same size of APPS, the elongation at break decreased as the PI segment content were increased, which, according to Figure 12, increased the tensile strength.

Regarding the effect of the molecular size of APPS on mechanical properties, Figures 12 and 13 showed that, for the same PI content, with increased size of APPS (from $M_{\mathrm{n}}$ of 859 to $M_{\mathrm{n}}$ of 1619), both tensile strength and elongation at break decreased. Such effect was more profound with the elongation at break when $M_{\mathrm{n}}$ increased from 859 to 1152 , accordingly the elongation at break dropped from $324 \%$ to $183 \%$.

Within the scope of this study, in designing such PIS copolymer, Figure 12 showed that for the same PI content, the use of small $M_{\mathrm{n}}$ of APPS would lead to high tensile strength. While Figure 13 showed that for the same PI content, small sized APPS would lead to high elongation at break. There 
figures also revealed that a low content of PI is preferred for the copolymer to have good elongation property.

Overall $M_{\mathrm{n}}$ of the PIS copolymer is another factor that affects the elongation at break. Since the overall $M_{\mathrm{n}}$ of the copolymers were not significantly different (section 3.2), Table IV did not compare the elongation at break in terms of overall $M_{\mathrm{n}}$. The $M_{\mathrm{n}}$ of APPS, being a partial component of the copolymer, is not likely to be of significant effect. Therefore, the effect of APPS and PI contents seems to be more influential to the elongation at break, as appeared in Table IV. Table IV showed that increased APPS content (or reduced PI content) would increase the elongation at break. It seems that these two figures (Figures 12 and 13) may serve as a good reference for the strategy in the design of this type of PIS copolymer.

\section{YOUNG'S MODULUS}

The Young's modulus (Figure 14, Table IV) of the PIS copolymers exhibited similar pattern to that of the tensile strength. Figure 13 showed that when the PI content was increased in each series of PIS copolymers having the same $M_{\mathrm{n}}$ of APPS, the Young's modulus increased accordingly. However, at low content $(<25 \%)$ of PI, the effect of APPS size was minor and little variation of the Young's modulus was observed in this region (15-25\%). The influence of molecular size of APPS on Young's modulus became more profound when PI content was increased to 30 and $35 \%$. The fact that due to the high value of Young's modulus of the PI homopolymer, not surprisingly, high PI content would lead to high Young's modulus is understandable.

Comparing copolymers with the same PI content, Figure 14 showed that the Young's modulus decreased with the increase of APPS molecular size, as the tensile strength did in Figure 12. For high $M_{\mathrm{n}}$ (1619) of APPS, the Young's modulus did not change appreciably as the PI content was increased from 15 to $35 \%$. It was quite a different story with the low $M_{\mathrm{n}}$ (859 and 1152) of APPS for PI content of 30 and $35 \%$ as mentioned above. Although it would be interesting to know how did the molecular size of APPS, in the soft segment, influence the mechanical properties this way, definitive explanation in discussing the effect of APPS molecular size is premature at this stage, and is currently under investigation.

\section{RUBBER PROPERTY}

For a polymer to exhibit rubber property, frequently it is better that the material has a high elongation at break, accompanied with low values of tensile strength and Young's modulus, while being able to resume its original shape upon the release of the stress applied. Considering data presented above, only copolymers with less than $20 \mathrm{wt} \%$ of PI content were expected to exhibit rubber property.

Sample sheets of dimensions 50 by 5 by $2 \mathrm{~mm}$, were prepared for stretching tests. The sample sheets were stretched to twice their original lengths, and then released. The test sheets retracted quickly to 1.0 and 1.2 times the original length for PIS-859-15 and PIS-859-20 respectively within one minute. Other sample sheets were either broken during the test, or were not able to resume their original lengths. This result was in accordance with the morphological studies stated above that, microphase separation existed in these two copolymers (PIS859-15 and PIS-859-20), as the FESEM micrographs, glass transition temperatures and light transmittance data have shown.

When the PIS copolymer contained more than $25 \mathrm{wt} \%$ of PI (the hard segment), the copolymers exhibited high tensile strength and Young's modulus with low elongation at break and behaved more like a material with plastic properties. Takeichi et al. ${ }^{13}$ made similar conclusion in their report that at PI content higher than $36 \%$, their poly(urethane-imide) behaved like plastics.

In this study, only the stretch-retract test was carried out, while other elastic properties remain to be discovered. However, it seems fair to say at this stage that, the above observations have shown that, PIS copolymers with rubber or plastic property, or property in between, can be designed by manipulating the components in the formulation (i.e. APPS $M_{\mathrm{n}}$, type of PI and content).

\section{CONCLUSIONS}

Three series of PIS copolymers with various lengths of APPS segment of polysiloxane were prepared in this study. The synthesis process proposed in this research is straightforward, which involved mainly simultaneous condensation of diamine pairs of APPS and m-BAPS with PMDA. FESEM showed that the PIS-1152 and PIS-1619 series copolymers with high hard PI segment content (20 to $35 \mathrm{wt} \%$ ) and all of the PIS-859 copolymers exhibited microphase separation. The three series of copolymers all exhibited the properties of thermoplastic elastomer by DMA test, which has the advantage of being easily reused by simple heat mixing, extrusion and/or injection molding. The copolymers of PIS-859-15 and PIS-859-20 were found to possess rubber properties. The thermal and mechanical properties of the PIS copolymer were affected by the PI hard segment content as well as the molecular size of APPS in the soft segment. These can be manipulated in designing the PIS copolymers for various applications.

Received: September 4, 2007

Accepted: October 31, 2007

Published: December 18, 2007

\section{REFERENCES}

1. A. Y. Coran and R. P. Patel, "Thermoplastic Elastomers," 2nd ed., in Thermoplastic Elastomers, G. Holden, R. P. Quirk, N. R. Legge, and H. E. Schroeder, Ed., Chapter 7 Hanser Publishers, Munich, 1996.

2. R. J. Spontak and N. P. Patel, Curr. Opin. Colloid Interface Sci., 5, 333 (2000).

3. S. J. Clarson and J. A. Semlyen, "Siloxane Polymers," PTR Prentice Hall, New Jersey., 1993, pp 567-615. 
4. M. Kajiyama, M. A. Kakimoto, and Y. Imai, Macromolecules, 23, 1244 (1990).

5. C. E. Sroog, Prog. Polym. Sci., 16, 561 (1991).

6. M. Hasegawa and K. Horie, Prog. Polym. Sci., 26, 259 (2001).

7. H. Yeganeh, B. Tammai, and I. Ghazi, Eur. Polym. J., 38, 2179 (2002).

8. M. Barikani, S. Mehdipour-Ataei, and H. Yeganeh, J. Polym. Sci., Part A: Polym. Chem., 39, 514 (2001).

9. B. Tamami and H. Yeganeh, J. Polym. Sci., Part A: Polym. Chem., 39, 3826 (2001).

10. H. Yeganeh and M. Barikani, Polym. Int., 49, 514 (2000).

11. H. R. Kricheldorf, T. Wollhein, C. E. Koning, H. G. WerumeusBuning, and V. Altstädt, Polymer, 42, 6699 (2001).

12. H. H. Yeganeh and M. A. Shamekhi, Polymer, 45, 359 (2004).

13. T. Takeichi, K. Ujiie, and K. Inoue, Polymer, 46, 11225 (2005).

14. I. Yilgor and J. E. McGrath, Adv. Polym. Sci., 86, 1 (1988).

15. Y. Yamada and N. Furukawa, Polym. J., 29, 923 (1997).

16. E. Rogers, D. Rofrigues, A. Brennan, G. L. Wilkes, and J. E. McGrath, Contemp. Polym. Sci., 7, 47 (1992)

17. N. Furukawa, Y. Yamada, and Y. Kimura, High Perform. Polym., 9, 17 (1997).
18. S. Andre, F. Guida-Pietrasanta, A. Rousseau, and B. Boutevin, J. Polym. Sci., Part A: Polym. Chem., 39, 2414 (2001).

19. S. Andre, F. Guida-Pietrasanta, A. Rousseau, B. Boutevin, and G. Caporiccio, J. Polym. Sci., Part A: Polym. Chem., 40, 4485 (2002).

20. S. Andre, F. Guida-Pietrasanta, A. Rousseau, B. Boutevin, and G Caporiccio, J. Polym. Sci., Part A: Polym. Chem., 42, 200 (2004).

21. S. Andre, F. Guida-Pietrasanta, A. Rousseau, B. Boutevin, and G. Caporiccio. J. Polym. Sci., Part A: Polym. Chem., 43, 2237 (2005).

22. S. Andre, F. Guida-Pietrasanta, A. Rousseau, B. Boutevin, and G. Caporiccio, Macromol. Chem. Phys., 205, 2420 (2004).

23. S. L. Jwo, W. T. Whang, and W. C. Liaw, J. Appl. Polym. Sci., 74, 2832 (1999).

24. S. L. Jwo, W. T. Whang, T. E. Hsieh, F. M. Pan, and W. C. Liaw, J. Polym. Res., 6, 175 (1999).

25. W. C. Liaw and K. P. Chen, J. Polym. Res., 14, 5 (2007).

26. C. Lü, Z. Wang, F. Liu, J. Yan, and L. Gao, J. Appl. Polym. Sci., 100, 124 (2006).

27. W. C. Liaw and K. P. Chen, Eur. Polym. J., 43, 2265 (2007).

28. A. Tiwari, A. K. Nema, C. K. Das, and S. K. Nema, Thermochim. Acta., 417, 133 (2004).

29. S. D. Bruck, Polymer, 6, 319 (1965). 